\title{
On the Versatility of the Competence Acquired through Immersion Program
}

\author{
Shaban Barimani \\ Department of English Language Teaching and Linguistics, Islamic Azad University, Sari Branch, Iran
}

\begin{abstract}
In this study it was attempted to determine whether the students learning a second/foreign language through an 'immersion program' can use the acquired competence in a versatile manner or their use of the acquired competence is subject dependent and subject-specific. To find the answer, two groups of students from two immersion schools in Mysore, India were chosen. Having secured their homogeneity through a standard proficiency test (Flyers) developed by Cambridge University, the researcher administered the appropriate tests to measure their ability in using the acquired second language at two levels of comprehension and production in two different situations: Met - their educational setting - and Unmet - the real life situation. The obtained data were analyzed through the application of $t$-test and the results revealed that the difference between the learners' ability in using the acquired competence in second language in different situations is not significant. So, the researcher could conclude that 'immersion program' can help learners use the acquired competence in second language in a versatile manner.
\end{abstract}

Index Terms - immersion program, learning, acquisition, SLA, versatility of language, competence

\section{INTRODUCTION}

Experiences have proven that some of the second or foreign language learners having studied a language for about four or more years at schools, when attended the target community were not able to communicate with the native speakers efficiently. A lot of instances of the case are available. For example, it was researched that students, who have studied French at high school for four years, when they attended Paris, they could not communicate with French people. As another instance, in Iran the students study English for about seven years at school - three to four hours in a weekbesides at least two years in university - two to three hours in a week, but they cannot communicate in English effectively. They gain just some passive competence in skills like reading and writing and more or less in vocabulary and grammar. It seems the main cause of the problem goes back to the methods of foreign/second language teaching which have been implemented; as, most of the methods mostly focus on teaching forms.

Immersion program can alleviate the mentioned problems created by the aforementioned approaches. As it has been experienced by many countries such as Canada, Australia, Japan and so on, through immersion program the learners can get both linguistic competence as the knowledge of language form empowering them to use language form correctly and communicative competence as the ability to use language correctly and appropriately. Metaphorically speaking, the competence which is obtained through the approaches other than immersion approach is like a dry and porous sponge. The pores are the deficiencies in ability to use the acquired knowledge properly. But the competence acquired through immersion approach is a sponge which is saturated and without the mentioned pores. It means that through immersion program learners acquire not only the knowledge of language form i.e., linguistic competence but also the appropriateness of language use i.e., communicative competence.

\section{A. Operational Definition of Versatility}

"Versatile use", as used in this study, refers to the ability to use the acquired second language for purposes other than their academic ones; that is, using second language for communication with people out of their school milieu or around subjects other than their subject matters. Following this assumption, the researcher divided the situations in which the learners may need to use the second language into 'met' and 'unmet' ones. By 'met' situations, he means using the second language in the classroom to answer or ask questions around the subjects covered in the target language or using the second language orally or in written form when they are taking their routine tests and quizzes.

The other use to which the acquired second language can be put is its use out of their classroom environment and around the subjects which have not been covered in their classes. Using the acquired second language for a live communication with others in written form or orally, participating in discussions on topics other than those they had already covered in their textbooks and in their classes, reading and comprehending texts such as newspapers, magazines, novels, etc. are some instances of using the acquired second language in 'unmet' situations. So, by 'unmet' the researcher means the ones which are new, novel and not already experienced by the learners.

\section{B. Objective of this Study}

The main goal of most approaches and methods of teaching a second/foreign language is to help their learners to use the acquired/learned language for the purpose of communication in situations out of their educational milieu. 
Researches have shown the goal is not gained that satisfactorily. The main purpose of this study is to determine the extent to which the students are able to use the acquired second language in a versatile manner. Naturally, the learners who study their school subjects through medium of a second language gradually acquire the second language associated with the subjects they are instructed such as math, science, and so on. The question posed by the researcher is whether they are also able to use the acquired competence in second language in a 'versatile' manner - both in met and unmet situations - or their use of the second language is strictly subject -dependent. To get an even more elaborated answer to the question, the students' ability in comprehension and production separately was studied.

\section{Research Questions and Hypotheses}

To survey the effect of immersion program on versatile use of the acquired competence in second language, one major and two minor research questions were posed and their corresponding null hypothesis and sub-hypotheses were formulated.

The major question: Can learners use the acquired competence in a versatile manner - in met and unmet situations or is it subject dependent and subject - specific?

The first minor question: Is there any difference between the learners' ability in the comprehension of the acquired second language in a versatile manner - in met and unmet situations?

The second minor research question: Is there any difference between the learners' ability in the production of the acquired second language in versatile manner -in met and unmet situations?

Following the above questions the related null and sub hypotheses are formulated as:

The null hypothesis: There is no difference between the learners' ability in using the acquired second language in 'met' and 'unmet' situations.

The first sub-hypothesis: There is no difference between the learners' ability in the comprehension of the acquired second language in versatile manner - in met and unmet situations.

The second sub-hypothesis: There is no difference between the learners' ability in the production of the acquired second language in versatile manner - in met and unmet situations.

\section{THEORETICAL FOUNDATION}

\section{A. Definition of Immersion Program}

Immersion program is defined as a method of foreign or second language instruction in which the regular school curriculum is taught through the medium of the target language.

One of the main characteristics of this program is 'at least 50 percent of instruction during a given academic year must be provided through the second language for the program to be regarded as immersion. Programs in which one subject and language arts are taught through the second language are generally identified as an enriched second language programs." (Fred Genesee, 1987)

Jim Cummins (2009) tries to look at "Immersion Program" from a different perspective and believes it is used in two different ways. He claims,

In the first sense 'immersion programs' are organized and planned forms of bilingual education in which students are 'immersed' in a second language instructional environment with the goal of developing proficiency in two languages. First language instruction is typically introduced within a year or two of the start of the program and forms an integral part of the overall plan. In its second sense, the term 'immersion' refers to the immersion of immigrant or minority language children in a classroom environment where instruction is conducted exclusively through their second (or third) language. He adds immersion program is a form of bilingual education that immerses students in a second language instructional environment for between $50 \%$ and $100 \%$ of instructional time with the goal of developing fluency and literacy in both languages.

Unlike a traditional language course where the target language is the subject material, language immersion uses target language as a tool. In other words, in this method the target language is not the subject of instruction, but it is the vehicle for content instruction as well as the object of instruction. For example, in English immersion program, English is not the subject of instruction; rather it is the medium through which a majority of school's academic content is taught.

\section{B. The Origin of Immersion Program}

There is a general agreement on Canada as the birth place of immersion program. For instance, Walker and Tedick (2000), believe that language immersion program originated in Canada about 40 years ago and is today "a language education program model used for a variety of purposes and across a wide range of social, cultural, and political contexts" (p. 6).

Mike Bostswick (2001) states that although bilingual education can be traced back to $3000 \mathrm{BC}$, the form of bilingual education called immersion education that they use at Katoh is generally accepted to have started in Quebec, Canada. Melikoff et al. (1972) also believe that the origin of immersion program is in Canada. They argue that the origins of publicly-funded immersion education in Canada were in St. Lambert, Quebec, in the 1960s. An initial group of 12 parents in St. Lambert met in October of 1963 to discuss their concerns regarding the failure of the existing education system to produce graduates with a communicative knowledge of French. Their concerns were expressed within the 
context of growing recognition by Quebec Anglophones of the importance of the French language in Quebec and in Canada. Olga Melikoff, one of the founding members of the St. Lambert parents group, reported that in 1963, the St. Lambert parents believed that "their children were being shortchanged and should have the opportunity to become 'bilingual' within the school system since it was so difficult to achieve this outside of school." After two years of meeting with other parents, of lobbying their school board, and of consulting language learning and teaching experts, the parents group finally obtained the reluctant permission of the school board to set up one experimental French immersion kindergarten class in September, 1965. The initial years of the 'experiment' were not easy, but the idea caught on and has subsequently spread across Canada (Stern, 1990) and to languages other than French.

So it can be claimed that Immersion education is most widespread and long - established in Canada. In Canada a Full immersion program means a bilingual program in which a second language (SL) is learned through other areas of curriculum and the two languages share equal time - and which includes an initial period of total immersion in which the entire instruction is in L2. Total immersion, the initial language 'bath' which begins a full immersion program, is thought to be a necessary component of program design if the proper immersion effect is to be experienced (Melikof et al, 1972).

\section{Characteristics of Immersion Program}

The very outstanding characteristic (some take it as an advantage) of immersion program is the teaching of a second language along with its culture and content without the application of the learners' first language.

Johnson and Swain (1997) mention eight characteristics of immersion programs as follows:

- The L2 is a medium of instruction.

- The curriculum is the same as the local L1 curriculum.

- Overt support exists for L1.

- The program aims for additive bilingualism.

- Exposure to the L2 is largely confined to the classroom.

- Students enter with similar (and limited) levels of L2 proficiency.

- The teachers are bilingual.

- The classroom culture is that of the local L1 community.

Immersion program is not an easily employed method. In comparison to other modern or innovative methods, this program needs the committed supports of many to be characterized as a successful program. So implementation of this program may create some struggles on the side of learners, teachers, or even parents. In general, according to Myriam Met (1987) a successful immersion program can be characterized by 1) administrative support 2) community and parental support 3) qualified teachers 4) appropriate materials in the foreign language 5) time for teachers to prepare instructional materials in the language 6) ongoing staff development.

\section{Types of Immersion Program}

Since the first immersion program in Canada, a number of different immersion programs have been implemented all over the world. Immersion programs are categorized in different categories based on two factors: age and extent

- Age: It refers to the time at which the program is initiated. In terms of time of initiation, immersion program is classified into four groups:

- Early Immersion: In this type of immersion commencing at the age of 5 or 6, students begin learning a second language in pre - school, kindergarten, or first grade of primary school.

- Middle Immersion (delayed immersion): It is initiated at the age of 9 or 10 when the students are at the later primary school.

- Late Immersion: It starts some time between the ages of 11 and 14 when the learners are at the secondary school.

- Late Late immersion: It begins at the university level.

- Extent: It refers to the percentage of curricular content covered in the L2. Based on this factor immersion programs can be divided into two types:

- Total Immersion: The programs in which the entire curriculum is taught in the L2 are classified as total or full immersion. In this type of immersion almost $100 \%$ of class time is in the foreign language. Subject matters are taught in foreign language. Target language is the only medium of instruction. In situations where comprehension is hampered, the teachers apply some techniques like dramatization, demonstration, definition, and use of realia, to resolve incomprehensibility.

- Partial Immersion: In partial immersion program about half of the class time is spent in teaching the subject matters in the foreign language. In other words, at least $50 \%$ of the curriculum is delivered through the target language.

\section{METHODOLOGY}

\section{A. Design and Sampling}

In terms of research method, this study falls into the category of "quantitative" research and its design is a longitudinal. 
In terms of sampling, it is both 'availability or convenience sampling' and 'purposive sampling'. It is 'availability sampling' since the samples selected from two schools in Mysore, India for this study are the most convenient and available ones for the researcher. It was neither economically nor logistically possible for the researcher to choose samples from other cities in India. On the other hand, it is 'purposive sampling' since the subjects were chosen based on the purpose of the study.

\section{B. Participants}

In this study, in order to provide a logical and data-based answer to the research questions, two homogenous groups of students of two genders, male and female, from two immersion schools named St. Joseph's Primary and St. Joseph's Central schools in Mysore, India were selected. They were nominated as group one (GI) and group two (GII). Having eliminated the outliers from the groups, the researcher could finally select 40 students from each class i.e. 80 altogether from the two aforementioned immersion schools as the main participants of the study. Both groups were studying in English-medium schools and were learning English as a by-product of school instructions. It is worth mentioning that the participants were not aware of the research procedures.

\section{Instrumentation}

In this study three 'paper and pencil' tests were used for different purposes: homogeneity determination, measurement of the extent of the subjects' ability in using the acquired second language in 'met' situations, and determination of the learners' ability in using the acquired second language in 'unmet' situations. To achieve the first goal, the researcher applied the YLE (Young Learners English) series produced by Cambridge University. It is at three different levels: "Beginners", "Movers", and "Flyers". To secure the homogeneity of the participants, considering the level of the participants, the researcher used the "Movers". It was composed of two main parts: "Listening" and "Reading \& Writing".

To achieve the other two goals, the researcher constructed two new tests on two aspects of production and comprehension. Having constructed the tests, he gave them to parallel classes to the target classes as pre-test to determine the appropriateness of each item. After scoring the papers, he analyzed each item in terms of item facility, item difficulty, and item discrimination.

Like any other newly developed test, these tests also required to be validated and their reliability needed to be estimated. Since they were Norm - Referenced Tests (NRT), their validity could be determined through criterionrelated validity. So the researcher used 'Flyers' the standard test produced by Cambridge University to calculate the coefficient validity of the newly developed tests. The obtained coefficient validities $\left(r_{x y}=0.73\right)$ and $\left(r_{x y}=0.68\right)$ confirm the validity of the tests. The reliability of these tests was estimated through applying the KR $\mathbf{2 1}$ formula. The estimated reliability of these tests $(\mathrm{r} \approx 0.65)$ and $(\mathrm{r} \approx 0.71)$ show that they can be regarded as reliable tests, too.

In these tests the students' ability in comprehension and production of grammar, vocabulary, reading and collocation in met and unmet situations was measured.

\section{Procedure}

To carry out this study, the following procedures were followed:

First, two groups of second standard students from two immersion schools were selected randomly. It was ascertained that all subjects had already passed Lower Kindergarten and Upper Kindergarten in English medium centers and being non-native English speakers. Being from two different educational centers, the participants were definitely required to be homogenized. Therefore, they were given a standard test namely YLE produced by Cambridge University as pre-test to secure their homogeneity. For this purpose, the "Movers" was applied. To test the homogeneity of the two groups, the researcher applied a $t$-test analysis the results of which appear in Table 1 .

TABLE 1:

$T$ - TEST FOR PRE-TEST SCORES FOR HOMOGENEITY OF TWO GROUPS

\begin{tabular}{|l|l|l|l|l|l|}
\hline Groups & $N$ & $M$ & $S$ & $d f$ & t. observed \\
\hline G I & 40 & 45.075 & 6.054 & \\
\hline$G$ II & 40 & 44.90 & 8.198 & 78 & 0.913 \\
\hline$P<0.05$ & \multicolumn{4}{|c|}{ t. critical = 2.000 } \\
\hline
\end{tabular}

According to this table, the obtained $t$ - value ( $t$. observed) was 0.9139 with concern of the degree of freedom of 78 and the level of significance of 0.05 , is smaller than the $t$-critical (2.000). So, it was concluded that the two groups of students of the Primary and Central St. Joseph's Schools, were homogeneous.

After the groups were proved to be homogenous, the researcher administered the two tests on second language to measure their ability in using and comprehending the acquired second language in two met and unmet situations with an interval. The obtained scores were compared and interpreted to achieve the final result.

\section{E. Data Collection}


The researcher collected data by attending some classes in two immersion schools in Mysore, India personally at different times. At first he distributed the proficiency test papers. Later on, he distributed the two other tests with an interval measuring their ability in using the acquired second language in two different situations (met and unmet).

\section{F. Data Analysis}

Following the collection of data from the participants, the researcher condensed all the items into two categories of comprehension and production. Each category included items on grammar, vocabulary, reading, and collocation. The data obtained from the participants were tabulated and transferred to Excel spreadsheet for descriptive and inferential statistical analyses. To verify the hypotheses, the data obtained from the whole participants was subjected to the t-test method to compare the means obtained from the two groups. All statistical procedures were carried out applying the $t$ test formula with alpha set as 0.05 . The primary aim of this study was to examine carefully the versatility in learners' second language competency acquired through an immersion program. In fact, the researcher wished to determine whether the learners can use the acquired second language in versatile manner or it is subject dependent.

\section{RESULTS}

Having scored the papers, the researcher put the obtained data in three different categories as follows.

\section{A. The Comparison of the Learners' Ability in "Using” the Acquired Second Language Competence in 'Met' and 'Unmet' Situations}

Having computed the means and standard deviations of the two sets of scores of two tests through the Excel software, the researcher could make a comparison between the learners' ability in using the acquired second language in different situations. So, the scores of the two different tests measuring the learners' ability in using the acquired second language in two different 'met' and 'unmet' situations (versatile manner) were subjected to $t$ - test formula and the results are presented in Table 2.

TABLE 2:

T - TEST FOR VERSATILE USE OF THE ACQUIRED SECOND LANGUAGE

\begin{tabular}{|l|l|l|l|l|l|}
\hline Situation & $N$ & $M$ & $S$ & $d f$ & t. observed \\
\hline Met & 80 & 65.44 & 7.89 & \multirow{2}{*}{} \\
\hline Unmet & $\mathbf{8 0}$ & $\mathbf{6 1 . 9 3}$ & $\mathbf{1 1 . 6 8}$ & $\mathbf{1 5 8}$ & $\mathbf{0 3 1}$ \\
\hline $\boldsymbol{P}<\mathbf{0 . 0 5}$ & \multicolumn{5}{|c|}{ critical $=1.98$} \\
\hline
\end{tabular}

According to the Table 2, the $t$. observed equaled 0.031 which is far too less than the $t$. critical which is 1.98 with the level of significance of $P<0.05$. It shows that the difference between using the second language in two different situations i.e., 'met' and 'unmet' is not statistically significant. So, it can be claimed that the learners who acquire a second language through immersion program will be able to produce and understand it in both 'met' and 'unmet' situations. In other words, their ability in comprehension and production of the acquired second language is not subject dependent. Consequently, the researcher can confirm his null hypothesis about the learners' ability in versatile use of the acquired second language which said 'There is no difference between the learners' ability in using the acquired second language in 'met' and 'unmet' situations'.

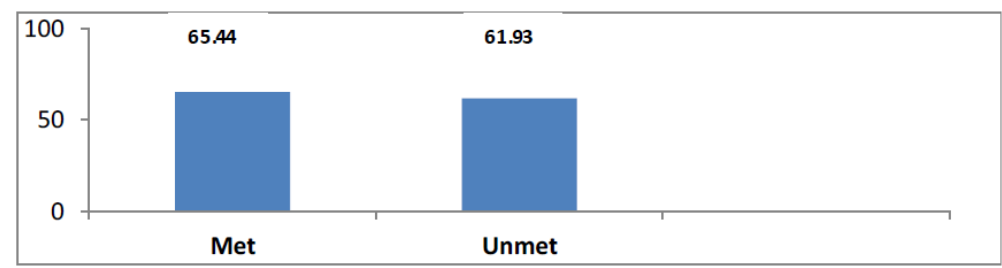

Figure 1: Means of using the acquired second language in 'met' and 'unmet' Situations

\section{B. The Comparison of Learners' Ability in Versatile "Comprehension" and "Production" of the Second Language}

In the previous section (4.1) the researcher made a comparison between the subjects' mean scores through the application of the $t$-test formula to determine their general ability in using the acquired second language. As we observed, since the $t$. observed (0.031) was smaller than the $t$. critical (1.98), no difference between second language use in two situations was found. In addition to this outcome, the researcher was interested in finding out whether there is any difference in the comprehension and production of the acquired second language in 'met' and 'unmet' situations or not. To meet this goal, the scores of the tests on versatile use and understanding of the second language were broken into 'comprehension' and 'production'. Then they were put in the $t$-test formula; the results are displayed in the following tables. In table 3 the learners' ability in versatile comprehension of the acquired second language is shown. 
TABLE 3:

T - TEST FOR VERSATILE COMPREHENSION OF THE ACQUIRED SECOND LANGUAGE

\begin{tabular}{|l|l|l|l|l|l|}
\hline Situation & $N$ & $M$ & $S$ & $d f$ & t. observed \\
\hline Met & 80 & 71.83 & 8.74 & & \multirow{2}{*}{} \\
\hline Unmet & 80 & 67.01 & 12.72 & 158 & 0.010 \\
\hline$P<0.05$ & \multicolumn{5}{|c|}{ t. critical $=1.98$} \\
\hline
\end{tabular}

As Table 3 shows, the $t$. observed (0.010) is much less than the $t$. critical (1.98). So the difference between the learners' ability in the comprehension of the acquired second language in the two 'met' and 'unmet' situations is insignificant. Thus the related sub hypothesis which was saying "There is no difference between the learners' ability in comprehension of the acquired second language in 'met' and 'unmet' situations” is supported.

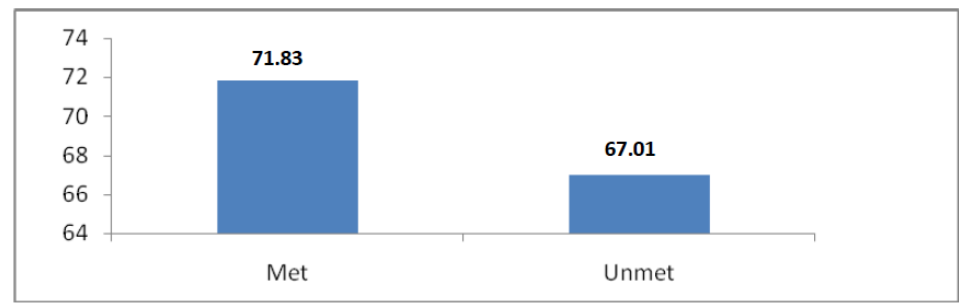

Figure 2: Means of scores in versatile comprehension of second language

In table 4 the learners' ability in versatile production of the acquired second language is shown.

TABLE 4:

T - TEST FOR VERSATILE PRODUCTION OF THE ACQUIRED SECOND LANGUAGE

\begin{tabular}{|l|l|l|l|l|l|}
\hline Situation & $N$ & $M$ & $S$ & $d f$ & t. observed \\
\hline Met & 80 & $\mathbf{5 9 . 3 0}$ & $\mathbf{9 . 7 3}$ & \multirow{2}{*}{ (158 } \\
\hline Unmet & $\mathbf{8 0}$ & $\mathbf{5 7 . 0 3}$ & $\mathbf{1 2 . 6 6}$ & $\mathbf{0 . 2 5 2}$ \\
\hline $\boldsymbol{P}<\mathbf{0 . 0 5}$ & t. critical $=1.98$ \\
\hline
\end{tabular}

This table also reveals an insignificant difference between the learners' ability in producing the second language in two different - met and unmet - situations since the $t$.observed (0.252) is smaller than the $t$. critical (1.98). So the sub hypothesis about the versatile production of the acquired second language is confirmed. As it said "There is no difference between the learners' ability in producing the acquired second language in 'met' and 'unmet' situations."

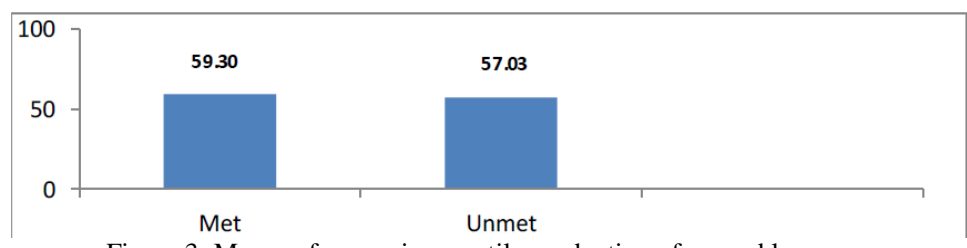

Figure 3: Means of scores in versatile production of second language

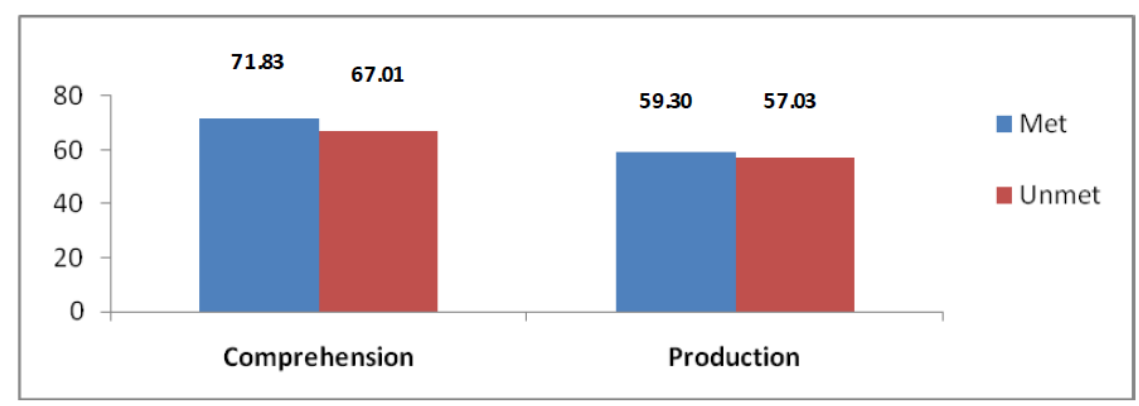

Figure 4: Means of versatile comprehension and production in met and unmet situations

\section{DISCUSSION AND CONCLUSION}

The main question of this study 'Can learners use the acquired competence in a versatile manner or is it subject dependent and subject-specific? investigated the students' ability in using the acquired second language in the 'met' and 'unmet' situations. As it was previously clarified, by 'met' situations, the researcher meant those in which the learners were exposed to a second language or they had already experienced it such as school milieu, classroom, and subject materials. By 'unmet', he meant the situations out of the school milieu. The ones in which the students will require to use the target language (the medium of instruction) 'receptively' and 'expressively'. According to Table 2, the obtained 
$t$. observed (0.031) computed through the application of the $t$-test formula on the means of the two tests is less than the $t$. critical value (1.98). It shows the difference between these two situations is not significant. Thus, the researcher accepted his null hypothesis: There is no difference between the learners' ability in using the acquired second language in 'met' and 'unmet' situations.

This finding can be considered as one of the most significant results of this study. All methods and approaches attempt to teach the learners a foreign/second language in a way that they can use the learned language in the real life situations. As the review of most of such methods shows, a large number of them failed in achieving this goal. One of the main reasons can be the gap between the environment in which the learners are taught the language and the real life environment in which they use the language, i.e., the educational environment may not match the characteristics of the real one. The other reason might be the contents through which the target language is presented. As it is quite normal in language teaching process, any new language is presented through content. The contents selected to bear language may be contrived and unreal.

On the contrary, the finding of this study shows that immersion program is successful in providing second language learners who are proficient both in educational setting and in real life situations. The result related to the main question tells us that what portion of the second language a learner has acquired in his class along with his learning the subject matters, he can use in the real life situations as well. It happens so in immersion education because the environment in which they are exposed to the target language is very close to the real environment. Further, the contents are not fake since they are the subject matters and the text books.

It can be justifiably claimed that the goal of language acquisition by immersion program is directly in line with the learners' future needs to a second language in their future life. Second language is presented in contexts and frameworks which are directly correlated with the contexts in which they will need to use the acquired language.

One of the ultimate goals in teaching/learning a second language is to make learners proficient enough to use the acquired/learned target language in the real life communication. Unfortunately the outcomes of many researches don't prove such success. Contrary to the expectations, most of the learners fail in establishing a successful communication when they are located in the target language community.

As it was shown in this study, the difference in the students' ability in producing and comprehending the acquired second language in two 'met' (their educational milieu) and 'unmet' (out of their educational milieu, real life) situations are not significant. It denotes that what the students acquire of the target language along with learning the regular subject matters can be used in classroom, in interaction with the peers and teachers, and out of their educational settings for a live communication as well. For instance, in Indian community the researcher finds educated people with a high proficiency in English as a second language who experienced no formal specific instruction in English except in their schools and universities in the light of immersion program implementation, either total or partial.

So, through immersion program, achieving the very important goal of second language acquisition can be guaranteed. In this case, the researcher can claim that the learners' competence in SL through immersion program in relation to second language acquisition is generalizable enough.

The outcome of this study can prove the claim that immersion program can be entitled as a second language acquisition approach (method). Since through the application of this method, the students can gain a kind of competence in second language which enables them to use it for communication properly.

In comparison to other methods which normally focus on teaching an SL, immersion program is quite successful to make the learners proficient in SL as well as to help them to gain mastery on the content.

One of the main distinctions of immersion program from the other methods is in having the learners proficient both in their general English and ESP. Instruction of all subjects in SL (English) provides an opportunity for them to learn ESP along with acquiring general English.

\section{IMPLICATIONS}

- One implication can be not recommending the immersion program to be used in any context (school or institute) with similar assumption and expectation. So implication of this program in EFL context is not supported because studying on limited number of students selected from two educational complexes in ESL context cannot provide sufficient evidence for the adequacy of immersion program in EFL context.

- Immersion program can be applied as the only instructional program by the teachers for the purpose of second language teaching, not mixed with other school program(s). Unlike some educational centers where the students receive the instruction half day in L1 and in another half in L2. In the two chosen schools where the researcher has done his study, students were exposed to the total immersion program and had all their school programs only in the target language (L2). However, in the combined L1 and L2 situations, it might make students feel tired and they could not benefit from the immersion program. The program will be successful and of benefit to the language learners, if it is used as an individual and independent program.

- Based on what the researcher found in this study and his own long experience as an EFL instructor, he recommends that for the EFL learners, the partial immersion program or communicative language teaching method with an active approach to grammar can be more beneficial than the total (full) immersion. However, an explicit teaching of grammar would be of benefit to the EFL students because they can learn and use it along with the activities they do 
around the syllabus. In an EFL environment, especially where learners are not exposed to the second language outside the class, communicative courses of language instructions can also be successful because learners pay attention mostly to language and not to the content and learn the second language by doing related tasks in the class.

\section{A. Implications for English-medium Schools}

The results of this study clearly showed that studying school subject matters through English is a very effective way of developing competence in English. The implications of this finding is that establishing English-medium schools both in EFL and ESL situations can serve the important purpose of teaching English as a by-product of schooling. Government educational organizations as well as Private educational institutions can adopt the immersion program which involves the teaching of school subjects through English.

\section{B. Implications for Securing the Cultural Safety of ELT Program}

Many Eastern countries in general and Islamic countries in particular are seriously concerned about the cultural consequences of teaching English in its western cultural context. This concern is accentuated by the profusion of western culture in the internationally- marketed ELT materials. The implication of this study for the cultural safety of ELT programs is that immersion program can be a very effective way of blocking these unwanted influences as the locally designed school textbooks can be free from the western cultural influences and reflect the ideals of education in the countries where they are used. Many subjects like Math and science are by their very nature totally free from unwanted cultural issues and many other subjects like social studies and history can be designed in such a way that the content of the courses are in line with the ideal goals of the educational systems in question. Helping the students achieve versatile competence in English without getting exposed to the unwanted cultural content of internationallymarketed ELT materials is an ideal for many educational policy makers around the world and this is what can be achieved through immersion program.

\section{Implications for Further Research}

The present research was concluded in Idea where English is used as a second language. The versatile competence achieved by the subjects of this study might be partially attributable to the reinforcement they received from the English speaking people in the social environment. Similar studies can be done in EFL situations where English is not used in the social context to see is the English-medium school students can achieve the same level of versatility in the use of English they learn in English-medium schools.

\section{REFERENCES}

[1] Bostwick, M. (2001). English Language Immersion in a Japanese School. In D. Christian \& F. Genesee (eds.), Bilingual Education. Alexandra: TESOL.

[2] Cummins, J. (2000). Immersion education for the millennium: What we have learned from 30 years of research on second language immersion. Available online: http://carla.acad.umn.edu/cobaltt/modules/strategies/immersion2000.pdf.

[3] Cummins. J. (2009). Bilingual and Immersion program. M Long and C. Doughty (Eds). Handbook of second language teaching. London: Blackwell.

[4] Genesee, F. (1987). Learning through two languages: Studies of immersion and bilingual education. New York: Newbury House.

[5] Holmes, J. (1991). Language and gender. Language Teaching, 24, 207-220.

[6] Lakoff, R. (1975). Language and woman's place. New York: Harper Colophon.

[7] Myriam Met, (1987). "Twenty Questions: The Most Commonly Asked Questions About starting a Foregn Language Immersion Program". ERIC Clearinghouse on Languages and Linguistics Washington DC. Proficiency (pp. 93-109). Cambridge: Cambridge University Press.

[8] Nilsen, A., et al. (1977). Sexism and language. Urbana, IL: National Council of Teachers of English.

[9] Sunderland, J. (2000). Issues of language and gender in second and foreign language education. Language Teaching, 37, 341359.

[10] Swain, M. \& Johnson, R. K. (1997). Immersion education: A category within bilingual education. In R. K. Johnson \& M. Swain (Eds.), Immersion education: International perspectives (pp. 1-16). NY: Cambridge University Press.

[11] Swain, M. (1984). A review of immersion education in Canada: Research and evaluation studies. In Studies on immersion education: A collection for United States educators, (pp. 87- 112). Sacramento: California State Department of Education.

[12] Tannen, D. (1986). That's not what I meant! How conversational style makes or breaks your relations with others, New York: William Morrow.

[13] Walker, C. \& Tedick, D. (2000). The complexity of immersion education: teachers address the issues. The Modern Language Journal, 84, 5-24. Retrieved March 14, 2009, from JSTOR.

Shaban Barimani was born in Iran in 1956. He received a Ph.D. in TEFL (Teaching English as a Foreign Language) from Mysore University in 2009 in India, an M.A. in TEFL (Teaching English as a Foreign Language) from Islamic Azad University in Iran, in 2001, and a B.A. in TEFL from UTE (University for Teacher Education) in Tehran, Iran in 1989.

As for his professional background, he is the chairman of the EFL department at Islamic Azad University, Sari Branch since 2009 up to now and a member of the faculty member of English Language and Linguistics in Islamic Azad University, Sari Branch since 
2002. Now, as chairman in TEFL and Linguistics and as an associate professor, he runs courses in Linguistics, Research, Testing, and methodology in Sari and Mazandaran Research and Technology branches of Islamic Azad University at the levels of BA and MA. 